\title{
Digitalization of ZISWAF Development in Indonesia
}

\author{
Fitri Nur Latifah ${ }^{1}$, Rusdi Hamka Lubis ${ }^{2}$ \\ fitri.latifah@umsida.ac.id' ${ }^{1}$, rusdihamka@ptiq.ac.id ${ }^{2}$ \\ Universitas Muhammadiyah Sidoarjo ${ }^{1}$, Institut PTIQ Jakarta, ${ }^{2}$
}

\begin{abstract}
The purpose of this research is to discuss ZISWAF (Zakat, Infaq, Shodaqah and Waqf) which involves collecting technology or better known as digitizing ZISWAF, The background of this study is because the potential of ZISWAF in Indonesia, as a country with the largest muslim population, still far from its realization which only reached 2 percent based on the data from 2011 to 2016. In the current industrial 4.0 era, smartphones and access to digital financial technology are common features for the society. Therefore, making ZISWAF collection and distribution through financial technology platform should not be difficult. The technology assistances also enable more accountable and more transparant transaction which is become important features for social fund governance. By using literature review method, this paper built ZISWAF's acquisition strategy that has been launched nationally.
\end{abstract}

Keywords: digitizing ZISWAF, smartphones, financial technology

\section{Pendahuluan}

Zakat, infak, sedekah dan wakaf (ZISWAF) adalah sebuah instrumen keuangan soasial Islam, yang memungkinkan adanya distribusi aliran kekayaan dari tangan orang kaya kepada orang miskin.[1] ZISWAF di samping memiliki dimensi ekonomi adalah merupakan sebuah kewajiban dan sebuah nilai ibadah yang berpahala. Bahkan dalam prespektif ilmu ekonomi, ZISWAF dapat pula dijadikan instrumen utama kebijakan fiskal. Meskipun sangat disayangkan bahwa hingga saat ini belum ada satu negara Islam pun di dunia ini yang menjadikan ZISWAF sebagai instrumen utama kebajikan fiskal. Serangkaian dengan instrumen zakat yang merupakan kewajiban ada juga instrumen yang berhukum sunah yakni infak, sedekah, dan wakaf, yang jamak disingkat menjadi Ziswaf (zakat, infak, sedekah, dan wakaf). Tatakelolanya biasa dilaksanakan menjadi satu badan meski mekanisme perolehan dan pendistribuasiannya berbeda sesuai dengan syariah Islam.

Di Indonesia permasalahan yang timbul padahal jumlah penduduk mayoritas muslim terbesar di dunia yakni adanya celah yang sangat besar antara potensi dan perolehan ziswaf. Selain itu, juga permasalahan pendistribusiannya juga belum bisa maksimal. Strategi untuk mengurangi celah tersebut adalah dengan cara digitalisasi proses penerimaan dan pendistribuasian serta pelaporan ziswaf, diharapkan denagn adanya digitalisais ziswaf ini bisa mempersempit celah yang ada.

Dunia zakat, infak, shadaqah dan wakaf sekarang mengalami perkembangan yang selaras dengan kemajuan teknologi. Teknologi digital telah dimanfaatkan dalam proses pengumpulan dan distribusi, manajemen, dan sebagai alat untuk pendidikan zakat. Pada sisi pengumpulan ada tiga platform digital yang tersedia untuk megumpulkan dana zakat, infaq, dan sedekah. [2] 
Pertama, platform internal adalah platform dikembangkan sendiri oleh lembaga zakat dalam bentuk situs website ataupun aplikasi. Basnas, sebagai contoh, menyediakan halaman website pembayaran zakat pada situs web-nya (baznas.go.id/zakatsekarang).

Kedua, platform eksternal yakni yang disediakan oleh mitra lembaga zakat untuk mengumpulkan dana Zis, beberapa lembaga zakat telah terlibat dengan beragam saluran pembayaran digital untuk membayar zakat seperti e-commerce, online crowdfunding, mesin pembayaran digital serta kode QR. Beberapa lembaga zakat telah berkolaborasi dengan platform e-commerce untuk menyediakan fasilitas untuk muzaki dalam membayar zakat, infaq, sedekah, dan wakaf (Ziswaf), dengan memanfaatkan platform ini muzaki bisa menjalankan platform Zis saat berbelanja daring. Di antara lembaga zakat yang ada telah bekerja sama dengan pihak ecommerace sebagai saluran pembayaran zakat rata-rata adalah Basnaz melalui : Tokopedia, Blibli, Bukalapak, KasKus, MatahariMall, dan Lazada. Dengan berbelanja dari muzaki secara langsung diingatkan untuk membayar Ziswaf. Selain pada platform tersebut, pembayaran zakat, infaq, sedekah, dan wakaf dapat dilakukan melalui platform crowdfunding online di antaranya kitabisa.com, Dompet Dhuafa, LazisMU, Rumah Zakat, dan NU Care-LazisNU. Melalui platform tersebut para muzakin dapat memonitor rencana zakat mereka, melihat distribusi zakatnya sehingga para muzaki memeiliki kepercayaan lebih ketika membayar zakat melalui platform tersebut.

Selain melalui platform yang tersedia dalam laman daring, digitalisasi pembayaran zakat, infaq, sedekah, dan wakaf ini ada mesin pembayaran tunai juga.Bisa menggunakan mesin semacam mesin mini ATM sehingga mempermudah muzaki untuk membayar zakat. Basnaz telah menyebarkan 1.700 mesin uang tunai, di antaranya $60 \%-70 \%$ sudah dipasangkan di sekitar 700 mal dan pusat perbelanjaan di area Jabodetabek. Pada mesin ini pelanggan juga bisa melakukan pembayaran rutin seperti pembayran listrik, pendidikan maupun pembayaran lainnya, karena sekarang ini sudah menjadi tren di masyarakat pembayaran sudah tidak melibatkan uang tunai.

Perintah zakat adalah sebuah kewajiban seorang muslim [3], kewajiban ini yang tidak hanya termasuk ibadah mualamalah tetapi masuk juga kepada tataran ibadah mahdah atau spiritual. [4] Allah SWT menyebutkan 32 kali untuk yang berkaitan dengan zakat ini berarti zakat adalah salah satu ibadah penting bagi seorang muslim, zakat bukan hanya bukti kepatuhan seorang muslim tetapi juga merupakan instrumen sosial ekonomi bagi masyarakat sehingga bisa tercapai cita-cika keadilasn sosial bagi seluruh rakyat Indonesia. [5]. Ziswaf merupakan sebuah instrumen kebijakan publik sebuah negara Islam.

Manajemen pengelolaan ziswaf pasti harus didasarkan pada undang-undang yang ada, untuk memastikan kewajiban ini dipenuhi oleh semua pihak tanpa penyimpangan. Pemerintah Indonesia mengeluarkan sebuah undang-undang yang mengatur tentang pengelolaan zakat di Indonesia yakni UU No, 23 tahun 2011. UU ini bertujuan agar pengelolaan zakat lebih efektif dan efisien dan tidak ada penyelewengan. Undang-Undang No, 23 tahun 2011 adalah revisi dari undang-undang sebelumnya yakni UU No, 38 tahun 1999 yang mana mengatur adanya formalitas yang berkaitan dengan ibadah sosial. Proses ijtihad ini yang membuat amandemen undang-undang dan diharapkan untuk lebih membawa kemaslahatan buat umat secara keseluruhan.

Penduduk Indonesia pada tahun 2018 jumlah penduduk muslim di Indonesia mencapai $86,10 \%$ dari jumlah penduduk 265 juta orang, sedangkan jumlah muzaki pada lembaga zakat tercatat sebanyak 787.568 terdiri atas muzaki perorangan 119.332. Dengan jumlah yang besar tersebut mestinya dana zakat yang terhimpun optimal dengan dukungan amil zakat yang banyak yang telah khusus fokus menghimpun dan menyalurkan zakat[6]. 
Diperlukan manajemen pengelolaan Ziswaf secara lebih baik dan efisien di zaman sekarang ini, sesuai dengan kondisi dan kebutuhan di lapangan. Untuk mengakomodasi hal tersebit digitalisasi pengelolaan ziswaf sangat dipandang sebagai keputusan yang tidak bisa dihindari lagi.

Tabel 1. Penghimpunan Dana Sosial Islam Menurut Jenis OPZ Tahun 2017 (dalam Rp)

\begin{tabular}{|l|r|r|r|}
\hline \multicolumn{1}{|c|}{$\begin{array}{c}\text { Jenis organissis } \\
\text { pengelola zakat }\end{array}$} & Perolehan Zakat & \multicolumn{1}{|c|}{$\begin{array}{c}\text { Dana Sosial } \\
\text { Keagamaan } \\
\text { Lainnya }\end{array}$} & $\begin{array}{c}\text { Perolehan Infaq } \\
\text { dan Sedekah }\end{array}$ \\
\hline BAZNAS & $\mathbf{1 3 7 . 5 3 7 . 7 7 4 . 9 0 9}$ & $\mathbf{0}$ & $\mathbf{1 6 . 0 0 4 . 3 2 8 . 4 9 6}$ \\
\hline BAZNAS Provinsi & $\mathbf{4 0 8 . 0 6 1 . 3 9 4 . 5 8 7}$ & $\mathbf{6 . 0 8 8 . 1 0 0 . 7 8 5}$ & $\mathbf{3 4 . 0 2 1 . 6 9 3 . 8 8 6}$ \\
\hline BAZNAS Kab/Kota & $\mathbf{2 . 8 9 3 . 5 8 0 . 4 2 9 . 4 0 2}$ & $\mathbf{6 1 . 7 2 2 . 8 4 2 . 6 9 2}$ & $\mathbf{4 7 1 . 3 8 6 . 1 6 5 . 5 2 5}$ \\
\hline LAZ & $\mathbf{7 5 4 . 9 6 2 . 8 3 5 . 4 8 0}$ & $\mathbf{1 9 7 . 5 3 4 . 6 9 4 . 6 2 4}$ & $\mathbf{1 . 2 4 3 . 4 7 1 . 0 0 9 . 0 8 6}$ \\
\hline Total & $\mathbf{4 . 1 9 4 . 1 4 2 . 4 3 4 . 3 7 8}$ & $\mathbf{2 6 5 . 3 4 5 . 6 3 8 . 1 0 1}$ & $\mathbf{1 . 7 6 4 . 8 8 3 . 1 9 6 . 9 9 3}$ \\
\hline Grand Total & \multicolumn{3}{|c}{6.224 .371 .269 .472} \\
\hline
\end{tabular}

Berdasarkan tabel 1 kita bisa melihat dari sisi perolehan ziswaf, dari lembaga pengumpulannya, jumlah perolehan zakat tersendiri juga perolehan infaq dan sedekah juga perolehan dana keagamaan lainnya dengan total keselurihan Rp. 6.224.371.269.472. [7]

Tabel 2. Pertumbuhan Penghimpunan Dana zakat, infak dan sedekah

\begin{tabular}{|c|c|c|}
\hline Tahun & Pertumbuhan (\%) & $\begin{array}{c}\text { Jumlah zakat, infak, } \\
\text { sedekah (Miliar } \\
\text { Rupiah) }\end{array}$ \\
\hline 2002 & 0.00 & 63.39 \\
\hline 2003 & 24.70 & 85.28 \\
\hline 2004 & 76.00 & 150.09 \\
\hline 2005 & 96.90 & 295.52 \\
\hline 2006 & 26.28 & 373.17 \\
\hline 2007 & 98.30 & 740.00 \\
\hline 2008 & 24.32 & 920.00 \\
\hline 2009 & 30.43 & 1200.00 \\
\hline 2010 & 25.00 & 1500.00 \\
\hline 2011 & 15.27 & 1.729 .00 \\
\hline 2012 & 27.94 & 2.212 .00 \\
\hline 2013 & 19.30 & 2.639 .00 \\
\hline 2014 & 25.05 & 3.300 .00 \\
\hline 2015 & 10.71 & 3.653 .27 \\
\hline 2016 & $\mathbf{3 7 . 3 4}$ & 5.017 .29 \\
\hline & Rata-rata & $35.84 \%$ \\
\hline
\end{tabular}

Sumber : PuskaBaznas “Outlook Indonesia 2018” 
Berdasarkan tabel 2 kita bisa melihat dari sisi kenaikan perolehan ziswaf, selalu meningkat dari tahun ke tahun dengan rata-rata kenaikan 35.84\%. Diharapkan dengan adanya digitalisais ziswaf kenaikan ini akan semakin meningkat tajam dan bisa memperkecil gap antara penerimaan dan potensi perolehan ziswaf.

Setelah data antara potensi dan realisasi penghimpunan zakat dikumpulkan dari tahun ke tahun dapat dikatakan celah yang ada masih tinggi antara perolehan dan potensi ziswaf, dengan kata lain masih sangat minimnya keberhasilan amil zakat maupun pengelola ziswaf dalam mengumpulkan ziswaf. Untuk bisa mempersempit celah atau gap yang ada perlu ada strategi yang tepat dalam manajemen pengelolaan ziswaf ini sehingga tercapai hasil yang maksimal.

\section{Metode}

Dalam penelitian ini merupakan literature review terhadap beberapa sumber bacaan mengenai pengelolaan ziswaf. Data-data kami dapatkan dari buku-buku dengan tema ziswaf, sumber-sumber berita, situs resmi lembaga amil zakat maupun literatur pendukung lainnya yang tersebar baik di jurnal nasional maupun jurnal internasional. Semua tulisan yang ada kami ringkas dan kami tulis kembali agar bisa memberikan gambaran strategi apa yang akan dilakukan untuk peningkatan dan penengmbangan manajemen pengelolaan digitalisasi ziswaf di Indonesia.

\section{Pembahasan}

Diskusi dan penelitan tentang ziswaf ini adalah topik kajian yang menarik dan sudah banyak sekali dilakukan baik di Indonesia maupun dalam skala global. Dikarenakan kewajiban akan zakat juga peranan ziswaf dalam sebuah perekonomian sangatlah penting didukung pula dengan adanya UU No.38 Tahun 1999 tentang pengelolaan zakat [8]

Tulisan kami sebelumnya, tentang "Analisis Strategi Pengemabangan ZISWAF di Indonesia terdapat 6 (enam) strategi pokok yang dapat dikembangkan dalam mencapai sasaran strategis ziswaf yakni (1) Digitalisasi Ziswaf, (2) Dewan Keuangan Inklusif, (3) Pengembangan Database, (4) Implementasi Regulasi, (5) Otomatisasi zakat, (6) Insentif pajak bagi muzaki. Sehingga digitalisasi ziswaf ini dianggap sangatlah perlu mencapai posisi teratas dalam pengembangan strategi untuk pencapaian sasaran ziswaf'.[9]

Secara umum, manajemen pengelolaan ziswaf memiliki tiga kegiatan penting, yaitu penghimpunan, pengelolaan, dan penyalurnya.[10] Kegiatan pengumpulan atau penghimpunan meliputi semua kegiatan dalam proses pengumpulan dana ZISWAF dari muzakki dan wakif, mulai dari sosialisasi atau pemasaran hingga penyimpanan dana ZISWAF yang terkumpul, sedangkan penyalurannya adalah semua kegiatan yang terkait dengan penyaluran dana ZISWAF dari muzaki (orang yang membayarkan zakat) dan wakif (pihak yang mewakafkan harta) kepada mustahik dan mauquf 'alaih, terutama pada program-program sektor sosial seperti program sosial, pendidikan, kemanusiaan dan lain sebagainya. Lebih dari itu, sebagai salah satu rencana aksi untuk memasukkan dana zakat dan wakaf yang merupakan bagian dari instrumen keuangan Islam dalam value chain, maka distribusi dana zakat dan wakaf dapat disalurkan untuk mendukung sektor riil pada suatu negara, khususnya industri halal. Sedangkan kegiatan pengelolaan antara lain mencakup kegiatan perencanaan, manajemen SDM, manajemen keuangan serta monitoring kegiatan dan evaluasi kegiatannya. Sementara itu, ekosistem utama yang mempengaruhi program kegiatan di sektor ZISWAF terdiri dari aspek sumber daya manusia (SDM), kesadaran masyarakat, regulasi (peraturan) dan kelembagaan, serta aspek riset dan pengembangan $(\mathrm{R} \& \mathrm{D})$ dan teknologi. [11] 
Dalam pengelolaan ziswaf secara umum tantangan pengelolaan ziswaf kita ada beberapa hal , pertama SDM. Pekerjaan sebagai amil zakat belumlah menjadi pekerjaan yang bisa menjadi tujuan khusus oleh anak muda zaman sekarang, meski ada beberapa pendidikan khusus untuk menjadi amil, sehingga amil biasanya hanya untuk pekerjaan sampingan saja. Pengetahuan dan kemampuan amil dirasakan belum maksimal.[12]

Tantangan kedua, pemahaman fikih dari amil juga belumlah sebaik yang dibutuhkan. Masih berkutat dalam kajian fikih lama dan banyak yang belum aplikatif dengan perkembangan zaman. Zaman teknologi yang sering disebut era industri 4.0 melibatkan peranan teknologi dalam pengelolaan manajemen ziswaf. Sedangkan perlu pengkajian fikih lebih dalam berijtihat atau menetapkan hukum pada beberapa produk peghimpunan maupun penyaluran ziswaf.

Tantangan selanjutnya, rendahnya kesadaran masyarakat dalam membayar ziswaf. Umat Islam memang umat yang mayoritas di Indonesia, tetapi dalam kesadaran mengeluarkan ziswaf belumlah maksimal. Zakat sebagian hanya mengetahui dan membayar sekedar zakat fitrah saat bulan Ramadan. Mekanisme ziswaf sebagai sebuah instrumen pemberdayaan masyarakat dan pemerataan ekonomi seharusnya lebih ditingkatkan lagi sosialisasinya kepada masyarakat, agar masyarakat semakin memahami betapa pentingnya ziswaf untuk sebuah kesejahteraan masyarakat. Sosialisasi dan pemahaman pembayaran ziswaf ini seharusnya melibatkan peranan teknologi agar efektif dan efisien. Baik dari segi iklan, sosialisasi, pengumpulan maupun penyalurannya.

Tantangan keempat, rendahnya teknologi yang dipakai. Belum semua teknologi dipakai dalam pengembangan manajemen ziswaf. Hanya sebatas metode sederhana. Dalam perkembangan sekarang ini sudah mulai berkembang kolaborasi dengan berbagai pihak yang mempunyai teknologi lebih maju contohnya dengan menggunakan aplikasi pada smartphone, mobile banking, ATM beras, mini ATM, QR code dan sebagainya. Sehingga menyalurkan ziswaf sudah lebih mudah tidak harus datang ke pihak amil untuk menyetorkan ziswaf. Dalam transaksi ATM maupun mobile banking sekarangpun customer langsung ditawarkan apakah bersedia berdonasi atau membayar ziswaf.

Tantangan yang kelima, belum adanya sistem informasi yang bisa saling menghubungkan antara satu amil dengan amil yang lain sehingga bisa saling berkoordinasi dan berkolaborasi dalam strategi peningkatan pengelolaan ziswaf. Dengan adanya sistem informasi yang baik transparansi juga pasti akan lebih terjaga.[13].

Pada era sekarang ini generasi lebih muda lebih banyak menggunakan gadget atau smartphone dalam kesehariannya. Peranan teknologi dalam pengembangan strategi manajemen ziswaf sangatlah penting. Dari sisi pengumpulannya kita bisa lihat bagaimana kolaborasi beberapa platform seperi e-commerce sudah melibatkan unsur kampanye sosial bagi para customernya contohnya GO-Jek yang menaruh menu Go-Give sebagai menu sosial dimana disana ditampilkan pihak yang membutuhkan bantuan, apakah untuk biaya pendidikan, biaya kesehatan, biaya hidup dan lain sebagainya. Disana akan ditampilkan profil penerima bantuan dan bagaimana perjuangan penerima bantuan yang sudah maksimal tetapi masih belum terselesaikan masalahnya. Sehingga pihak customer bisa memberikan donasi langsung sesuai dengan pihak yang akan diberikan, sesuai dengan preferensi dari pelanggan masing-masing. Perolehan dana dan penyalurannya nantinya juga akan sangat transparan bisa dilihat langsung pada menu itu juga.

\section{Kesimpulan}

Digitalisasi dalam pengelolaan zakat, Infak, Sedekah, dan Wakaf sudah merupakan kewajiban yang tidak bisa ditawar lagi, dengan semakin pesatnya perkembangan teknologi dan 
kemudahan fitur-fitur pembayaran Ziswaf yang ditawarkan berbagai platform yang ada diharapkan mampu memberikan kontribusi positif yang sangat besar bagi perolehan Ziswaf dan pendistribusian yang tepat sasaran. Sehingga manajemen pengelolaan Ziswaf yang baik di Indonesia makin baik dan berkembang menuju kesempurnaan. Dengan penerapan teknologi informasi yang baik pasti menunjang tingkat akuntabilitas dan transparansi lembaga secara nasional. Dengan strategi tersebut diharapkan distribusi Ziswaf akan lebih efektif dan efisien sehingga gap antara penerimaan dan penyalurannya menjadi lebih kecil dibandingkan sekarang gap potensi dengan perolehannya belum sampai 2\% dan butuh banyaknya usaha untuk meningkatkan penerimaan ziswaf.

\section{References}

[1] Hamzah, "Pendayagunaan Zakat Pada Budan Amil Zakat Nasional Dalam Meningkatkan Kesejahteraan Umat," 2009.

[2] I. S. Beik, "Implementasi MEKSI dan Zakat,” Jakarta, Jun-2019.

[3] Yusuf Qardawi, Fiqhuz Zakat. Jakarta: Litera AntarNusa, 1993.

[4] D. Menguatkan and Z. Di, "Peran Strategis Organisasi Zakat Dalam Menguatkan Zakat Di Dunia 1 Didin Hafidhuddin," vol. 2, no. 1, pp. 1-4, 2011.

[5] L. M. G. Abdus Samad, "Development of Zakah and Zakah coverage in monotheistic faiths," 2010.

[6] I. Nurfalah and A. S. Rusydiana, "Digitalisasi Keuangan Syariah Menuju Keuangan Inklusif: Kerangka Maqashid Syariah,” Ekspansi J. Ekon. Keuangan, Perbank. dan Akunt., vol. 11, no. 1, p. 55, 2019.

[7] Badan Pusat Statistik, “Jumlah Penduduk Indonesia 2018," Jakarta, 2018.

[8] P. Taher, "Zakat dan Negara Studi Tentang Prospek Zakat dalam Meningkatkan Kesejahteraan Masyarakat denagn Berlakunya UU No.38 Tahun 1999 tentang pengelolaan Zakat," 2005.

[9] R. H. Lubis and F. N. Latifah, "Analisis Strategi Pengembangan Zakat, Infaq, Shadaqoh dan Wakaf di Indonesia (Analysis of Zakat, Infaq, Shadaqoh and Wakaf Development Strategies in Indonesia)," Perisai Islam. Bank. Financ. J., vol. 3, no. 1, p. 45, 2019.

[10] N. Huda, R. I. Idris, M. E. Nasution, and R. Wiliasih, Ekonomi Makro Islam, Pendekatan Teoritis, 1st ed. Jakarta: Kencana Prenada Media Group, 2009.

[11] Monzer Kahf, The Principle Of Socio-Economic Justice In The Contemporary. Malaysia, 1999.

[12] S. Mollah and M. Zaman, "Shari'ah supervision, corporate governance and performance: Conventional vs. Islamic banks,” J. Bank. Financ., vol. 58, pp. 418-435, 2015.

[13] Siti Zumrotun, "Peluang, tantangan, dan strategi zakat dalam pemberdayaan ekonomi umat," pp. 97-104, 2016. 